\title{
Exploring the Relationship between Adiponectin and Blood Pressure in Nigerian Children
}

\section{Chisom Adaobi Nri-Ezedi ${ }^{1}$ (), Henry Chima Okpara ${ }^{2}$, Kenneth Nchekwube Okeke ${ }^{*}$ (D), Ezinne Ifeyinwa Nwaneli1 ${ }^{(0)}$, Emeka Stephen Edokwe1 ${ }^{10}$, Sylvia Tochukwu Echendu3 ${ }^{3}$ (), Thomas Obiajulu Ulasi ${ }^{1}$ (i)}

\author{
${ }^{1}$ Department of Paediatrics, Faculty of Medicine, Nnamdi Azikiwe University, Awka, Nigeria \\ ${ }^{2}$ Department of Chemical Pathology, Faculty of Medicine, Nnamdi Azikiwe University, Awka, Nigeria \\ ${ }^{3}$ Life International Hospital, Awka, Nigeria \\ Email: *kenwados01@yahoo.co.uk
}

How to cite this paper: Nri-Ezedi, C.A., Okpara, H.C., Okeke, K.N., Nwaneli, E.I., Edokwe, E.S., Echendu, S.T. and Ulasi, T.O. (2022) Exploring the Relationship between Adiponectin and Blood Pressure in Nigerian Children. Open Journal of Endocrine and Metabolic Diseases, 12, 9-19.

https://doi.org/10.4236/ojemd.2022.122002

Received: December 6, 2021

Accepted: February 12, 2022

Published: February 15, 2022

Copyright ( 2022 by author(s) and Scientific Research Publishing Inc. This work is licensed under the Creative Commons Attribution International License (CC BY 4.0).

http://creativecommons.org/licenses/by/4.0/

(c) (i) Open Access

\begin{abstract}
Background: Adiponectin possesses essential physiological functions that protect against the onset of cardiovascular and metabolic diseases. Although several studies have discussed the association between adiponectin and Blood Pressure (BP) in adults and older adolescents. To the best of our knowledge, this is the first study to explore the relationship between adiponectin and $\mathrm{BP}$ among children in Africa. Significance: This novel discovery is expected to serve as a benchmark for future local studies in examining the role of adiponectin in cardiovascular disorders among Africans. Method: A cross-sectional study was conducted among 86 healthy children aged 4 to 11 years with normal BMI. BP values were measured and percentiles derived from the 2017 revised clinical practice guidelines of the American Academy of Paediatrics. Fasting blood adiponectin values were determined with ELISA, and the level of statistical significance was set at $\mathrm{p}<0.05$. Result: 86 children were comprised of $42(48.8 \%)$ males and $44(51.2 \%)$ females. The mean age of all subjects was $7.5 \pm 2.3$ years, while that of fasting adiponectin was $4.8 \pm 2.1 \mathrm{ng} / \mathrm{dl}$. There were no significant differences in the age, Body Mass Index, BP and adiponectin concentrations across gender. 69 (80.2\%) participants had normal BP while 5 (5.8\%) and $12(14.0 \%)$ had elevated BP and stage 1 hypertension. Mean adiponectin values for normal $\mathrm{BP}$, elevated $\mathrm{BP}$ and stage 1 hypertension were $5.1 \pm 2.1 \mathrm{ng} / \mathrm{ml}, 3.3 \pm 1.2 \mathrm{ng} / \mathrm{ml}$ and $4.1 \pm 1.9 \mathrm{ng} / \mathrm{ml}$ respectively ( $\mathrm{p}$-value $=$ 0.039). A significant negative correlation was observed between adiponectin and systolic BP independent of age, sex, and BMI. Although a negative correlation was noted between adiponectin and diastolic blood pressure, this
\end{abstract}


was not statistically significant. Conclusion: Adiponectin correlates negatively with systolic BP in young Nigerian children independent of age, Body Mass Index and gender. More studies are indicated to investigate this relationship in association with vital metabolic factors across different age groups in Africa.

\section{Keywords}

Adiponectin, Blood Pressure, Cardiovascular Diseases, Nigeria, Atherosclerosis, Hypertension

\section{Introduction}

Adiponectin is a 244-amino acid adipokine secreted exclusively by the adipose tissue [1]. It is the most abundant adipocytokine and accounts for approximately $0.01 \%$ of total plasma protein. Across different ethnicities, blood adiponectin concentration varies, and this variability is primarily dependent on distinct genetic composition [2] [3]. Recently, adiponectin has been the focus of intense research interest due to its vast physiological functions that play a crucial role in the pathogenesis of certain non-communicable diseases [4] [5]. These diseases, including cardiovascular diseases, type 2 diabetes mellitus, metabolic syndrome, and cancer, are cumulatively the leading causes of global death, with cardiovascular diseases solely constituting approximately fifty percent of these cases [6]. With escalating rates of adiposity reported worldwide, many affected individuals are expected to develop these diseases, further worsening the associated clinical burden.

One of the key metabolic risk factors of cardiovascular disorders is elevated Blood Pressure (BP) [6]. Annually, elevated BP accounts for approximately 19\% of global deaths [6]. The 2017 revised clinical practice guideline from the American Academy of Paediatrics defines normal BP in children aged 1 to 13 years as systolic and diastolic BP below the $90^{\text {th }}$ percentile for age, height and gender. Untreated, hypertension triggers the onset of atherosclerosis which progressively results in extensive damage to multiple organ systems. Although the symptomatology of cardiovascular diseases occurs later in adult life, several studies have illustrated a significant positive association between blood pressures in adults and children [7] [8]. One of these studies observed a higher predictive value of adult BP from a one-time measurement of systolic blood pressure in children aged 5 to 7 years compared to older age groups [8]. This highlights the importance of comprehensive blood pressure screening in early childhood.

Adiponectin plays a pivotal role in mitigating the onset of cardiovascular diseases [5]. Hypoadiponectinemia significantly correlates negatively with elevated blood pressures in hypertensive and normotensive subjects independent of age, gender and body mass index [9]-[15]. In Africa, particularly among the pediatric 
age group, the literature on this relationship is grossly limited. Owing to the variability in blood adiponectin values and the critical rise in the clinical burden of cardiovascular disease in Africa, it becomes imperative for local researchers to investigate the underlying pathophysiology to mitigate this disturbing trend [16].

\section{Materials and Methods}

\subsection{Study Area}

This study was conducted in Nnewi metropolis, the second-largest city in Anambra State, South-East Nigeria [17]. As of 2006, the estimated population in Nnewi was 391,227 . The ethnicity of most of its inhabitants is Igbo.

Study design: This study was a cross-sectional descriptive study.

Study population: School children aged $5-11$ years were enrolled in this study. The ages of the children enrolled were calculated using their last birthdays provided by the caregivers. The age range of $4-11$ years encapsulates the pre-pubertal stage of development in Nigerian children, thus obviating the confounding effect of puberty on adiponectin distribution [18] [19]. Children who did not give their assent and whose parents declined to give informed consent were excluded from the study. None of the selected subjects had any clinical features suggestive of chronic kidney or liver disease.

Sampling technique: Convenient sampling method was used to recruit the study subjects.

Statistical analysis: Statistical analysis was done using the Statistical Package for the Social Sciences version 22 (IBM Corp., Armonk, NY, USA). Categorical data were expressed as frequencies and percentages, while continuous data were presented as mean and standard deviations. To compare means between groups with parametric quantitative variables, student t-test and one-way analysis of variance (ANOVA) were applied. Pearson correlation test was used for the correlation of parametric quantitative variables. Linear regression models of both univariate and multivariate indices were adopted to adjust for possible confounding variables. The significance level was determined as $\mathrm{p}<0.05$.

\subsection{Ethical Consideration}

Ethical approval was obtained from the Research Ethics Committee of Nnamdi Azikiwe University Teaching Hospital, Nnewi. An informed written or oral consent was obtained from the caregivers, while assent was obtained from subjects above six years of age.

\subsection{Data Collection}

Anthropometric Measurements

\section{Weight}

The weights of the subjects were measured with a weighing scale (SMIC HEALTH SCALE, MODEL RGZ-120). Subjects were asked to remove their foot-wears 
and strip to their under-wears before the measurement of their respective weights. Weight in kilograms was noted with a steady scale pointer and recorded to the nearest $0.1 \mathrm{~kg}$.

\section{Height}

With subjects standing upright, height was measured with a stadiometer connected to the weighing scale (SMIC HEALTH SCALE, MODEL RGZ-120) and recorded to the nearest $0.1 \mathrm{~cm}$.

\section{Body Mass Index (BMI)}

BMI was calculated from the weight and the height using the formula weight $(\mathrm{kg}) /$ height $\left(\mathrm{m}^{2}\right)$. The gender- and age-specific BMI cutoff percentiles specified by the Centre for Disease Control and Prevention (CDC) growth reference chart for children were determined using the BMI percentile calculator for child and teen (metric version) [20] [21].

\section{Blood Pressure Assessment}

Blood pressures of all subjects were measured before blood was drawn for adiponectin assay. Amercury gravity sphygmomanometer was used to measure each participant's blood pressure three times with the average of these values used in the final analysis. According to the 2017 revised clinical practice guidelines of the American Academy of Paediatrics, systolic BP (SBP) and diastolic BP (DBP) were used to derive the blood pressure percentiles cutoffs for the different stages of BP [16]. Normal blood pressure was defined as SBP and DBP $<90^{\text {th }}$ percentile for children aged $1-13$ years; elevated $\mathrm{BP}$ as SBP and DBP $\geq 90^{\text {th }}$ to $<95^{\text {th }}$ percentile and stage 1 hypertension as $\mathrm{BP} \geq 95^{\text {th }}$ to $<95^{\text {th }}$ percentile +12 $\mathrm{mmHg}$.

\section{Adiponectin Assay}

The caregivers were instructed to ensure that their wards adhered to an overnight fast for a minimum of eight hours. This was confirmed on the day of the study, following which five millilitres $(5 \mathrm{ml})$ of whole venous blood was drawn and stored in labelled plain sample bottles. The sample bottles were spun in a centrifuge for about 10 minutes at 3000 revolutions per minute. Two millilitres $(2 \mathrm{mls})$ of the supernatant serum were harvested and stored at a minimum temperature of $-25^{\circ} \mathrm{C}$. Precautions were undertaken to avoid contamination and loss of bioactivity [22]. Total adiponectin was measured using Elabscience Human ADP/Acrp30 (Adiponectin) ELISA kits from Guangdong Science and Technology Industry Park, Wuhan, Republic of China (Catalogue No.: E-EL-H0004) [22]. The minimum detectable dose of the ELISA kit was $0.47 \mathrm{ng} / \mathrm{ml}$ with a detection range of $0.78-50$ $\mathrm{ng} / \mathrm{ml}$. The coefficient of variation was $<10 \%[22]$.

\section{Results}

Of the 86 subjects enrolled, 42 (48.8\%) were males. The mean age of all subjects was $7.5 \pm 2.3$ years with an age range of 4 to 11 years. Female subjects were slightly older than the males, but this was not statistically significant (Table 1). The mean systolic BP of all subjects was $91.3 \pm 11.5 \mathrm{mmHg}$, while that of diastolic BP was $58.9 \pm 9.7 \mathrm{mmHg}$. All subjects enrolled in this study had normal 
Table 1. Baseline characteristics of the study subjects.

\begin{tabular}{ccccc}
\hline & Total & Male & Female & p-value \\
\hline $\mathbf{n}$ & $86(100)$ & $42(48.8)$ & $44(51.2)$ & - \\
Age (years) & $7.5(2.3)$ & $7.2(2.2)$ & $7.8(2.3)$ & 0.259 \\
Weight (kg) & $25.2(6.8)$ & $24.5(7.0)$ & $25.8(6.6)$ & 0.377 \\
Height (cm) & $126.3(14.1)$ & $124.3(14.1)$ & $128.1(14.0)$ & 0.215 \\
BMI (kg/m $\left.{ }^{2}\right)$ & $15.4(1.0)$ & $15.4(1.0)$ & $15.5(1.1)$ & 0.805 \\
SBP (mmHg) & $91.3(11.5)$ & $91.9(10.8)$ & $90.7(12.2)$ & 0.634 \\
DBP (mmHg) & $58.9(9.7)$ & $60.1(9.8)$ & $57.8(9.5)$ & 0.271 \\
Adiponectin (ng/ml) & $4.8(2.1)$ & $4.7(2.0)$ & $4.9(2.2)$ & 0.542 \\
\hline
\end{tabular}

SBP: Systolic blood pressure; DBP: Diastolic blood pressure.

body mass indexes. No significant differences were observed between age, body mass index, systolic and diastolic BP, and adiponectin across gender (Table 1).

Blood Pressure and Adiponectin

Almost all the study participants had normal blood pressures (80.2\%). Among those with abnormal blood pressure, over $50 \%$ had stage 1 hypertension, with the male subjects constituting about two-thirds of these cases. A rise in blood pressure was significantly associated with a decrease in adiponectin, as shown in Table 2 and Figure 1, which demonstrated that normotensive subjects had approximately $2 \mathrm{ng} / \mathrm{dl}$ more adiponectin compared to those with elevated BP and stage 1 hypertension.

Using linear regression models, the negative correlation between adiponectin and blood pressure was further elucidated (Table 3 and Table 4). A unit rise in blood adiponectin value was associated with a significant decrease of about 1.3 $\mathrm{mmHg}$ in systolic blood pressure $(\beta=-1.316 ; \mathrm{C} / \mathrm{I}=-2.482$ to $-0.150 ; \mathrm{p}=$ $0.027)$. The correlation coefficient obtained was $-0.238\left(\mathrm{R}^{2}=0.057, \mathrm{p}=0.027\right)$. This negative linear relationship persisted following adjustments for sex, age, BMI as illustrated in Table 3. Although a negative relationship existed between adiponectin and diastolic blood pressure, this was not statistically significant (Table 4).

\section{Discussion}

There is limited data on the relationship between adiponectin and blood pressure among children of native African descent. This study aims to bridge that gap by evaluating this association among apparently healthy normal weight children within the pre-pubertal age range, thus decreasing to a significant extent the effect of known confounders [19]. Our study revealed a significant negative relationship between adiponectin and systolic blood pressure independent of age, gender and body mass index. This finding is consistent with most global reports conducted mainly in adults and adolescents of varying body sizes [9]-[15]. In a review, the authors noted a dose-response relationship between adiponectin 
Table 2. Association of the stages of blood pressure with adiponectin across study subjects.

\begin{tabular}{cccccc}
\hline Blood Pressure & $\mathbf{n}(\%)$ & $\begin{array}{c}\text { Males } \\
\mathbf{n}=\mathbf{4 2}\end{array}$ & $\begin{array}{c}\text { Females } \\
\mathbf{n}=\mathbf{4 4}\end{array}$ & $\begin{array}{c}\text { Adiponectin } \\
(\mathbf{n} / \mathrm{dl})\end{array}$ & p-value \\
\hline Normal & $69(80.2)$ & $32(46.4)$ & $37(53.6)$ & $5.1(2.1)$ & \\
Elevated & $5(5.8)$ & $2(4.0)$ & $3(60.0)$ & $3.3(1.2)$ & $0.039^{*}$ \\
Stage 1 & $12(14.0)$ & $8(66.7)$ & $4(33.3)$ & $4.1(1.9)$ & \\
\hline
\end{tabular}

${ }^{*} \mathrm{p}<0.05$.

Table 3. Linear regression analysis on SBP in relationship with serum adiponectin and other factors among Nigerian children.

\begin{tabular}{|c|c|c|c|c|}
\hline & \multirow[t]{2}{*}{$\beta$} & \multicolumn{2}{|c|}{ Confidence Intervals } & \multirow[t]{2}{*}{ p-value } \\
\hline & & Lower Bound & Upper Bound & \\
\hline \multicolumn{5}{|l|}{ Model 1} \\
\hline Adiponectin & -1.316 & -2.482 & -0.150 & $0.027^{\star}$ \\
\hline \multicolumn{5}{|l|}{ Model $1+$ Sex } \\
\hline Adiponectin & -1.302 & -2.477 & -0.0127 & $0.030^{*}$ \\
\hline \multicolumn{5}{|l|}{ Model $2+$ Age } \\
\hline Adiponectin & -1.404 & -2.597 & -0.120 & $0.022^{*}$ \\
\hline \multicolumn{5}{|l|}{ Model $4+$ BMI } \\
\hline Adiponectin & -1.336 & -2.511 & -0.161 & $0.026^{*}$ \\
\hline \multicolumn{5}{|c|}{ Model $5+$ Sex, Age, BMI } \\
\hline Adiponectin & -1.394 & -2.602 to -0.187 & & $0.024^{*}$ \\
\hline
\end{tabular}

${ }^{*} \mathrm{p}<0.05$.

Table 4. Linear regression analysis on DBP in relationship with serum adiponectin and other factors among Nigerian children.

\begin{tabular}{ccccc}
\hline & $\beta$ & \multicolumn{2}{c}{ Confidence Intervals } & p-value \\
\hline Model 1 & & Lower Bound & Upper Bound & \\
Adiponectin & -0.783 & -1.816 & 0.249 & 0.135 \\
\hline Model 1 + Sex & & & 0.273 & 0.147 \\
Adiponectin & -0.760 & -1.793 & 0.120 \\
\hline Model 2 + Age & & & 0.223 & \\
Adiponectin & -0.836 & -1.894 & 0.167 \\
\hline Model 4 + BMI & & & 0.308 & \\
Adiponectin & -0.721 & -1.749 & & 0.129 \\
\hline Model 5 + Sex, Age, BMI & & & & \\
Adiponectin & -0.806 & -1.851 & &
\end{tabular}




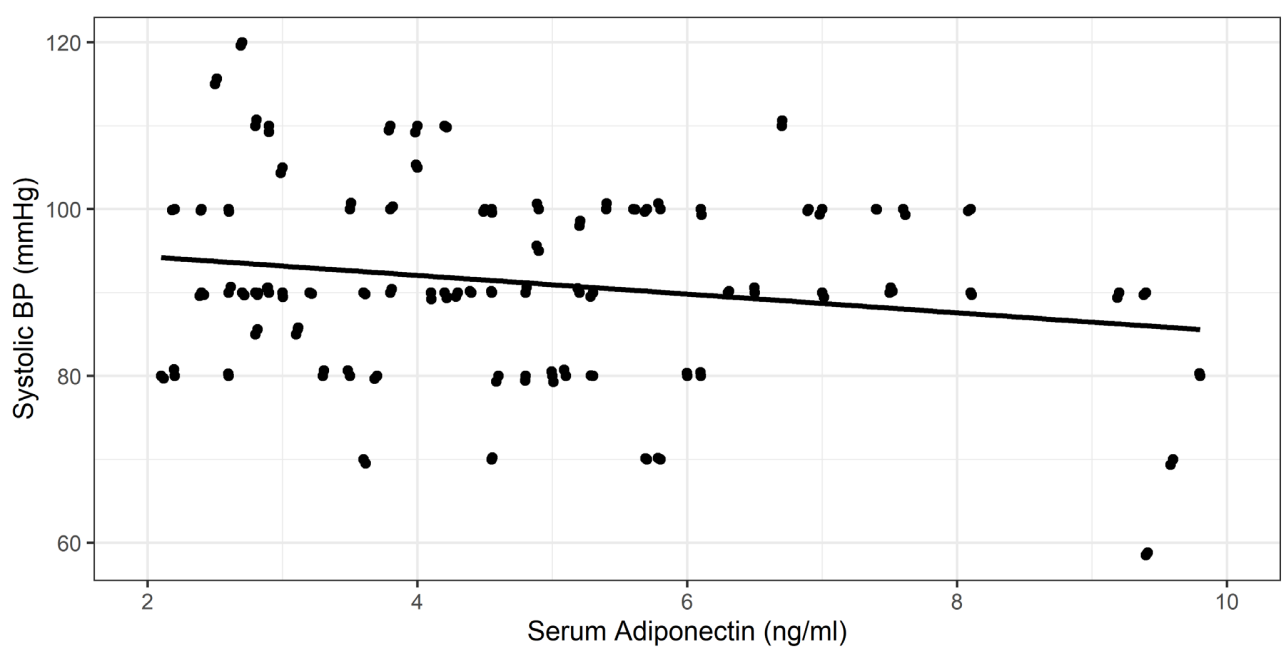

Figure 1. Linear relationship between serum adiponectin and systolic blood pressure.

and blood pressure which indicates that a $1 \mathrm{ug} / \mathrm{ml}$ rise in blood adiponectin value was associated with a $6 \%$ lower risk of hypertension (OR: 0.94; 95\% CI: 0.91 , 0.96: $\mathrm{p}<0.001$ ) [9]. This is consistent with our findings as we similarly obtained from our linear regression model that a unit rise in adiponectin value was significantly associated with a $1.2 \mathrm{mmHg}$ decrease in systolic blood pressure.

Adiponectin decreases cardiovascular disease risk through several underlying mechanisms that promote insulin sensitivity, boost lipid profile, arrest inflammatory changes and mitigate against atherogenesis [23] [24]. In animal studies, adiponectin further exerts a direct modulatory effect on blood pressure through the repair of micro endothelial damage and the production of nitric oxide [25]. A few other studies further surmised that angiotensin receptor antagonists indirectly acts by stimulating adiponectin production [26] [27]. In all, these studies strengthen adiponectin's regulatory role in modulating blood pressure, which is generally agreeable with our findings.

The mean adiponectin concentration of normotensive subjects was significantly higher than subjects with elevated blood pressure and stage 1 hypertension. This association corroborates with many similar reports and further adds to the body of growing evidence pertaining to the significant role of adiponectin in the pathogenesis of cardiovascular diseases. A systematic review observed that over $70 \%$ of the 48 studies reviewed reported a significant decrease in blood adiponectin of hypertensive subjects compared to normotensive subjects [9]. Furthermore, the weighted mean differences between these two blood pressure groups were independent of study design, age of the subjects, or body mass status [9]. Despite the dearth of literature from Africa, a similar study inclusive of African subjects with mixed ancestry tracked the blood pressures of over a thousand African American adults for a median of 7 years [11]. The authors demonstrated that male subjects with the highest adiponectin quartile had a significant decrease in incident hypertension and risk of blood pressure independent of body mass index. This finding was however not observed among the female co- 
hort. Although this study was conducted among adults, its outcome and our findings corroborate with global reports, further establishing the negative linear relationship between adiponectin and blood pressure even among African subjects.

Although we observed that the mean adiponectin values were generally lower among subjects with increased blood pressure, subjects with stage 1 hypertension had a slightly higher mean adiponectin value than subjects with elevated $\mathrm{BP}$. We hypothesized that this intriguing finding might be attributed to the slow rise in blood pressure stimulating overtime the adipocytes to produce more adiponectin in an attempt to mitigate against any deleterious effects. A similar theory was also proposed by Mallamaci et al. [28]. In their study, they observed a positive correlation between adiponectin and blood pressure. This report also corroborates other published works on the paradoxical rise of adiponectin in obese subjects, severe insulin-resistant states and increased mortality [29] [30] [31]. Further exploring the different isomeric forms of adiponectin and their respective actions in hypertensive states may shed further insight into this phenomenon. In contrast to most reports supporting the negative association between adiponectin and blood pressure, several studies found no correlation [32] [33].

Overall, the correlation coefficient of our linear regression models indicated a weak relationship between adiponectin and systolic blood pressure $(r=-0.238)$. In addition, the coefficient of determination accounted little for the variability in systolic BP. A similar observation was discussed in a systematic review by Hyun Kim and colleagues [9] in which they opined that cross-sectional studies conducted among the general population had lower correlations than comparative studies with hospital-based samples. Thus, the lower correlate value obtained in this study might be attributed to our study design and subjects enrolled from the community. In addition, known confounders such as insulin resistance and adiposity markers were not explored in this study, which may further account for the poor variability obtained. Nevertheless, this study is novel, with our findings on African children generally consistent with global reports.

\section{Conclusion}

Although we found a significant negative linear relationship between adiponectin and blood pressure independent of age, Body Mass Index and gender, more studies are needed to explore this effect with other known factors associated with cardiovascular and metabolic diseases within Africa.

\section{Conflicts of Interest}

The authors declare no conflicts of interest regarding the publication of this paper.

\section{References}

[1] Trujillo, M.E. and Scherer, P.E. (2005) Adiponectin-Journey from an Adipocyte 
Secretory Protein to Biomarker of the Metabolic Syndrome. Journal of Internal Medicine, 257, 167-175. https://doi.org/10.1111/j.1365-2796.2004.01426.x

[2] Miljkovic-Gacic, I., Wang, X., Kammerer, C.M., Bunker, C.H., Wheeler, V.W., Patrick, A.L., et al. (2007) Genetic Determination of Adiponectin and Its relationship with Body Fat Topography in Multigenerational Families of African Heritage. Metabolism, 56, 234-238. https://doi.org/10.1016/j.metabol.2006.09.019

[3] Menzaghi, C., Trischitta, V. and Doria, A. (2007) Genetic Influences of Adiponectin on Insulin Resistance, Type 2 Diabetes, and Cardiovascular Disease. Diabetes, 56, 1198-1209. https://doi.org/10.2337/db06-0506

[4] Gil-Campos, M., Cañete, R.R. and Gil, A. (2004) Adiponectin, the Missing Link in Insulin resistance and Obesity. Clinical Nutrition, 23, 963-974.

https://doi.org/10.1016/j.clnu.2004.04.010

[5] Hug, C. and Lodish, H.F. (2005) The Role of the Adipocyte Hormone Adiponectin in Cardiovascular Disease. Current Opinion in Pharmacology, 5, 129-134.

[6] Chigom, E. (1988) Noncommunicable Diseases. World Health Organization. https://www.who.int/news-room/fact-sheets/detail/noncommunicable-diseases

[7] Chen, X.L. and Wang, Y.F. (2008) Tracking of Blood Pressure from Childhood to Adulthood: A Systematic Review and Meta-Regression Analysis. Circulation, 117, 3171-3180. https://doi.org/10.1161/CIRCULATIONAHA.107.730366

[8] Sun, S.S., Grave, G.D., Siervogel, R.M., Pickoff, A.A., Arslanian, S.S. and Daniels, S.R. (2007) Systolic Blood Pressure in Childhood Predicts Hypertension and Metabolic Syndrome Later in Life. Pediatrics, 119, 237-246.

https://doi.org/10.1542/peds.2006-2543

[9] Kim, D.H., Kim, C., Ding, E.L., Townsend, M.K. and Lipsitz, L.A. (2013) Adiponectin Levels and the Risk of Hypertension: A Systematic Review and Meta-Analysis. $\mathrm{Hy}$ pertension, 62, 27-32. https://doi.org/10.1161/HYPERTENSIONAHA.113.01453

[10] Lambert, M., O’Loughlin, J., Delvin, E.E., Levy, E., Chiolero, A. and Paradis, G. (2009) Association between Insulin, Leptin, Adiponectin and Blood Pressure in Youth. Journal of Hypertension, 27, 1025-1032. https://doi.org/10.1097/HJH.0b013e32832935b6

[11] Kaze, A.D., Musani, S.K., Bidulescu, A., Correa, A., Golden, S.H., Bertoni, A.G., et al. (2021) Plasma Adiponectin and Blood Pressure Progression in African Americans: The Jackson Heart Study. American Journal of Hypertension, 34, 1163-1170. https://doi.org/10.1093/ajh/hpab101

[12] De Las Heras, J., Lee, S., Bacha, F., Tfayli, H. and Arslanian, S. (2011) Cross-Sectional Association between Blood Pressure, In Vivo Insulin Sensitivity and Adiponectin in Overweight Adolescents. Hormone Research in Paediatrics, 76, 379-385. https://doi.org/10.1159/000331462

[13] Shatat, I.F., Freeman, K.D., Vuguin, P.M., Dimartino-Nardi, J.R. and Flynn, J.T. (2009) Relationship between Adiponectin and Ambulatory Blood Pressure in Obese Adolescents. Pediatric Research, 65, 691-695. https://doi.org/10.1203/PDR.0b013e31819ea776

[14] Wang, H., Necheles, J., Birne, J.S., Li, Z., Xing, H., Tang, G., et al. (2012) Association of Adipokines with Blood Pressure in Rural Chinese Adolescents. Journal of Human Hypertension, 26, 493-501. https://doi.org/10.1038/jhh.2011.64

[15] Gómez-Díaz, R.A., Rodríguez-Moran, M., Mondragón-González, R., Wacher, N.H. and Guerrero-Romero, F. (2019) Adipocytokines and High Blood Pressure in Mexican Children. Endocrine Research, 44, 159-167. https://doi.org/10.1080/07435800.2019.1610771 
[16] Yuyun, M.F., Sliwa, K., Kengne, A.P., Mocumbi, A.O. and Bukhman, G. (2020) Cardiovascular Diseases in Sub-Saharan Africa Compared to High-Income Countries: An Epidemiological Perspective. Global Heart, 15, 15.

[17] Nnewi. Wikipedia. https://en.wikipedia.org/wiki/Nnewi

[18] Eyong, M.E., Ntia, H.U., Ikobah, J.M., Eyong, E.M., Uket, H., Enyuma, C., et al. (2018) Pattern of Pubertal Changes in Calabar, South South Nigeria. The Pan African Medical Journal, 31, Article No. 20.

[19] Nri-Ezedi, C.A., Ulasi, T., Chukwuka, J., Okpara, H., Ofiaeli, O., Nwaneli, E., et al. (2021) Serum Total Adiponectin in Healthy Pre-Pubertal Nigerian School Children. Nigerian Journal of Clinical Practice, 24, 821-827. https://doi.org/10.4103/njcp.njcp $427 \quad 20$

[20] Defining Childhood Weight Status. BMI for Children and Teens. CDC. https://www.cdc.gov/obesity/childhood/defining.html

[21] Child \& Teen BMI Calculator. CDC. https://www.cdc.gov/healthyweight/bmi/calculator.html

[22] ELISAs and ELISA Kits. Elabscience. https://www.elabscience.com/Products-elisa kits-61.html

[23] Ohashi, K., Ouchi, N. and Matsuzawa, Y. (2011) Adiponectin and Hypertension. American Journal of Hypertension, 24, 263-269. https://doi.org/10.1038/ajh.2010.216

[24] Yiannikouris, F., Gupte, M., Putnam, K. and Cassis, L. (2010) Adipokines and Blood Pressure Control. Current Opinion in Nephrology and Hypertension, 19, 195-200. https://doi.org/10.1097/MNH.0b013e3283366cd0

[25] Tanida, M., Shen, J., Horii, Y., Matsuda, M., Kihara, S., Funahashi, T., et al. (2007) Effects of Adiponectin on the Renal Sympathetic Nerve Activity and Blood Pressure in Rats. Experimental Biology and Medicine, 232, 390-397.

[26] Watanabe, S., Okura, T., Kurata, M., Irita, J., Manabe, S., Miyoshi, K., et al. (2006) The Effect of Losartan and Amlodipine on Serum Adiponectin in Japanese Adults with Essential Hypertension. Clinical Therapeutics, 28, 1677-1685.

https://doi.org/10.1016/j.clinthera.2006.10.012

[27] Ran, J., Hirano, T., Fukui, T., Saito, K., Kageyama, H., Okada, K., et al. (2006) Angiotensin II Infusion Decreases Plasma Adiponectin Level via Its Type 1 Receptor in Rats: An Implication for Hypertension-Related Insulin Resistance. Metabolism, 55, 478-488. https://doi.org/10.1016/j.metabol.2005.10.009

[28] Mallamaci, F., Zoccali, C., Cuzzola, F., Tripepi, G., Cutrupi, S., Parlongo, S., et al. (2002) Adiponectin in Essential Hypertension. Journal of Nephrology, 15, 507-511.

[29] Morrison, J.A., Glueck, C.J., Daniels, S., Wang, P. and Stroop, D. (2011) Paradoxically High Adiponectin in Obese 16-Year-Old Girls Protects against Appearance of the Metabolic Syndrome and Its Components Seven Years Later. The Journal of Pediatrics, 158, 208-214.E1. https://doi.org/10.1016/j.jpeds.2010.08.012

[30] Semple, R.K., Halberg, N.H., Burling, K., Soos, M.A., Schraw, T., Luan, J., et al. (2007) Paradoxical Elevation of High-Molecular Weight Adiponectin in Acquired Extreme Insulin Resistance Due to Insulin Receptor Antibodies. Diabetes, 56, 1712-1717. https://doi.org/10.2337/db06-1665

[31] Menzaghi, C. and Trischitta, V. (2018) The Adiponectin Paradox for All-Cause and Cardiovascular Mortality. Diabetes, 67, 12-22. https://doi.org/10.2337/dbi17-0016

[32] Snehalatha, C., Yamuna, A. and Ramachandran, A. (2008) Plasma Adiponectin Does Not Correlate with Insulin Resistance and Cardiometabolic Variables in Nondiabetic 
Asian Indian Teenagers. Diabetes Care, 31, 2374-2379.

https://doi.org/10.2337/dc08-1083

[33] Ivković, V., Jelaković, M., Laganović, M., Pećin, I., Vrdoljak, A., Karanović, S., et al. (2014) Adiponectin Is Not Associated with Blood Pressure in Normotensives and Untreated Hypertensives with Normal Kidney Function. Medicine, 93, e250.

https://doi.org/10.1097/MD.0000000000000250 